This article was published in European Food Research and Technology, 240(4), 763-773, 2015 http://dx.doi.org/10.1007/s00217-014-2381-y

\title{
Diterpenes in Espresso Coffee: Impact of Preparation Parameters
}

\author{
Marzieh Moeenfard ${ }^{\mathrm{a}}$. José Avelino Silva ${ }^{\mathrm{a}}$. Nuno Borges ${ }^{\mathrm{b}}$. Alejandro Santos ${ }^{\mathrm{b}}$. Arminda Alves ${ }^{\mathrm{a} *}$ \\ aLEPABE, Faculdade de Engenharia, Universidade do Porto, Rua Dr. Roberto Frias, 4200-465 Porto, Portugal \\ ${ }^{\text {b} F a c u l d a d e ~ d e ~ C i e ̂ n c i a s ~ d a ~ N u t r i c ̧ a ̃ o ~ e ~ A l i m e n t a c ̧ a ̃ o, ~ U n i v e r s i d a d e ~ d o ~ P o r t o, ~ R u a ~ D r . ~ R o b e r t o ~ F r i a s, ~ 4200-465 ~ P o r t o, ~ P o r t u g a l ~}$ \\ *Corresponding author: Telephone: +351-225081883; Fax: +351-225081449; E-mail: aalves@fe.up.pt
}

\begin{abstract}
The aim of the present study was to evaluate the effect of preparation conditions of espresso coffee (EC) on the diterpenes profile. ECs were prepared from roasted and ground (R\&G) Arabica coffee and analyzed for the content of cafestol and kahweol by liquid-liquid extraction followed by HPLC-DAD, as well as their lipid content. The main variables in the present study were: the water quantity, the amount of coffee, the particle size, the percolation time, the water temperature and pressure. Average cafestol, kahweol and lipid content of R\&G Arabica coffee were $467 \pm 20 \mathrm{mg} / 100 \mathrm{~g}, 638 \pm 33 \mathrm{mg} / 100 \mathrm{~g}$, and $15.1 \pm$ $0.1 \mathrm{~g} / 100 \mathrm{~g}$, respectively. Although all parameters influenced the diterpenes content of ECs (21 samples), the particle size and water quantity were the most significant ones. It was possible to reduce the total diterpenes from $58.8 \pm 0.7 \mathrm{mg} / \mathrm{L}(2.3 \mathrm{mg} / 40$ $\mathrm{mL})$ to $30.7 \pm 0.8 \mathrm{mg} / \mathrm{L}(1.2 \mathrm{mg} / 40 \mathrm{~mL})$ by varying the brewing conditions. The extraction yield of diterpenes and lipids were in the range of $1.5-2.5 \%$ and $7.0-9.0 \%$, respectively. Regarding total cafestol and kahweol, very fine particles seem to be more desirable for the production of highly concentrated brew $(2.3 \mathrm{mg} / 40 \mathrm{~mL})$ with cafestol and kahweol extraction yields of 2.8 and $2.9 \%$, respectively, than other studied ECs. On the other hand, samples brewed at $70{ }^{\circ} \mathrm{C}$ exhibited lower diterpenes content $(1.2 \mathrm{mg} / 40 \mathrm{~mL})$ and diterpenes extraction efficiency $(1.4 \%)$ with respect to all other considered parameters. This study clearly shows that parameters for coffee brew preparation may be changed to modify the diterpenes content of ECs according to the desired purpose.
\end{abstract}

Keywords Espresso coffee, Brewing, Diterpenes, Roasted coffee beans

\section{Introduction}

Coffee is a globally consumed beverage and can be prepared in different ways. One of the common coffee brewing techniques is the Italian "Espresso" which are consumed over than 50 million cups per days [1]. Espresso coffee (EC) is an intense beverage with special aroma made for immediate consumption [2]. For the preparation of espresso coffee, a limited amount of hot water $\left(90 \pm 5^{\circ} \mathrm{C}\right)$, under pressure $(9 \pm 2 \mathrm{bar})$, passes through a compressed finely roasted and ground coffee $(\mathrm{R} \& \mathrm{G}, 6.5 \pm 1.5 \mathrm{~g})$ in a short period of time $(30 \pm 5 \mathrm{~s})$ and produces a brew $(15-50 \mathrm{~mL})$ with strong taste and flavor topped with crema (dense foam layer) [1, 
3]. Originally, EC was an Italian beverage, but nowadays it is widely consumed in Latin European countries, United States and Japan [3].

Final quality of EC may vary from one cup to another one, depending on different factors such as coffee species, roasting degree [4], water quality [5], personal preferences [1], as well as the extraction device [6]. These factors may influence the coffee brew composition which resulted in ECs with different physicochemical and sensory properties. Lipids are one of the compounds exist in coffee which is important to the beverage flavor and is associated to various biological activities [7]. Coffee lipid is regarded as an important source of bioactive components from the kauran family, called diterpenes, mainly cafestol and kahweol [8]. These compounds may exist in free or esterified forms $[9,10]$. Total diterpene contents present in coffee range from $1.3-1.9 \%$ and $0.2-1.5 \%(\mathrm{w} / \mathrm{w})$ in green Arabica and Robusta coffee beans, respectively [11]. Coffee diterpenes are known for their effects on human health, as cafestol and, to a lesser extent, kahweol, have been related with the increase of serum cholesterol [12]. But on the other hand, positive health effects have also been attributed to diterpenes and data available in the literature point out the elevation of liver enzymes [13], antioxidant activity [14], anti-carcinogenic [15], anti-inflammatory [16] and anti-angiogenic properties [16, 17] as well as protective effects against aflatoxin B1 [18].

Coffee can be brewed in various ways depending on consumers' preference, but recently consumer choice for a particular type of coffee beverage have been affected by various parameters. People prefer to know more about the chemical composition of their coffee brew and the potential impact of specific compounds on their health [19]. Therefore during the past few decades, EC have caught more attention due to high consumption. It should be taken into account that apart from the popularity, coffee brews have biological importance due to the marker compounds like diterpenes.

EC is capable of delivering moderate levels of diterpenes, however there is limited information regarding the influence of parameters of brewing procedures on the levels of cafestol and kahweol per cup. Although the chemical composition of ECs as affected through different coffee/water ratio [20,21], particles size [21, 22], extraction temperature [21, 23, 24] and water pressure $[24,25]$ has already been reported, scarce information [21] were found in the literature with respect to diterpenes content of ECs prepared under different conditions. Considering the significant consumption of EC among European countries, studying the effect of operating conditions on diterpenes content of EC becomes relevant.

Regarding diterpenes in ECs, the most extensive study was carried out by Buchmann et al. [21] who studied the impact of grind size, water temperature, and coffee/water ratio on only cafestol concentration of EC and fresh brew prepared using a vending machine. They indicated significant effects of coffee/water ratio and particle size on cafestol content of ECs. Zhang et al. [26] focused on the cafestol extraction yield from different coffee brew mechanisms, namely boiled, French, mocha and Turkish coffee at different roast intensity. They observed the highest cafestol extraction yield (6.5\%) in French press brew prepared using light roasted beans.

Regarding coffee-shop espresso machines, one of the most used types of delivering ECs, there is no comprehensive study regarding the influence of several technological factors on cafestol and kahweol content of EC. On the other hand, to the best of our knowledge, the extraction yield of cafestol, kahweol and lipid in different ECs prepared with different conditions has not been documented so far. Therefore, this study is valuable for the modification of brewing procedures in order to adjust diterpenes concentration and cafestol/kahweol ratio in the final EC, which by its turn should be useful when data about diterpenes effects on health is robust enough to allow the establishment of safe or beneficial level of intake. 


\section{Material and Methods}

Chemicals and reagents

Individual standards of cafestol and kahweol (purity of $98 \%$ ) were purchased from ChromaDex (Irvine, CA, USA) and LKT Laboratories (MN, USA), respectively. HPLC grade acetonitrile and methanol, along with diethyl ether (purity of 99\%) and $n$ hexane (purity of 95\%) were acquired from VWR (BDH Prolabo, Belgium). Other used chemicals were potassium hydroxide with purity of approx. 85\% (Merck, Germany) and sodium chloride (Panreac Quimica, Spain). Filtered distilled water used for HPLC analysis was prepared by vacuum purification through $0.45 \mu \mathrm{m}$ filter membranes.

\section{Espresso coffee preparation}

Roasted Arabica coffee beans (100\% Coffea arabica, 2.34\% water content), packed in nitrogen-based protective atmosphere, were kindly supplied by a local company in Porto, Portugal. Roasted beans were ground by means of an automatic grinder (La Cimbali ${ }^{\circledR}$, grinder-doser $6 / \mathrm{SA}$ ) just before the EC preparation. The grinder provided different levels of grinding, designated from 1 to 15, for very fine to very coarse ground, respectively. For selecting the best grinding grades for EC preparation, $7.5 \mathrm{~g}$ of ground coffee at different grinding levels were brewed. The level of 3.3, which resulted in a percolation time of $21 \pm 3 \mathrm{~s}$, was selected as fine ground for further sample preparation. Consequently, the levels of 3.0 and 4.2 were selected as very fine and coarse grinds. Finer particles than level of 3.0 and coarser ones than level of 4.2 were impractical, due to unacceptable high or low extraction time. The particle size distributions for very fine, fine and coarse coffee grounds are presented in Fig. 1. Coffee beans were ground just before brewing, to keep sensorial properties, and ECs were prepared using a semiautomatic espresso machine (La Cimbali M31 Classic). A standard EC was prepared using 7.5 $\pm 0.2 \mathrm{~g}$ of finely R\&G Arabica coffee and water temperature fixed at $90 \pm 2{ }^{\circ} \mathrm{C}$ (temperature of water at the exit of the heating unit). For the preparation of an EC with a volume of $40 \mathrm{~mL}$, a pressure of around $9.0 \pm 0.2$ bar was necessary. The time of extraction was kept at $21 \pm 3 \mathrm{~s}$ [23].

The studied variables were $R \& G$ coffee weight $(6.5,7.5,8.5$ and $9.5 \mathrm{~g}$ ), particle size (very fine, fine and coarse ground), water quantity, equivalent to cup size $(30,40,50$ and $60 \mathrm{~mL})$, water temperature $\left(70,80\right.$ and $\left.90{ }^{\circ} \mathrm{C}\right)$, water pressure $(7,9$ and 11 and 14 bar) and percolation time (10,21 and $30 \mathrm{~s})$. For each variable, three coffee brews were prepared. ECs were transferred to polyethylene tubes and stored at $-22{ }^{\circ} \mathrm{C}$ until analysis. Regarding the diterpene content, all samples were submitted to four extractions. Lipid contents were expressed as a result of duplicate extractions.

Total lipid content of EC

The total lipid content in coffee brew was obtained according to Parenti et al. [6] with minor modifications. Briefly, $5 \mathrm{~mL}$ of EC was extracted with $5 \mathrm{~mL}$ of $n$-hexane for four times (mixed on vortex for $3 \mathrm{~min}$ ) and centrifuged at $4000 \mathrm{rpm}$ for $15 \mathrm{~min}$. The collected organic fraction was centrifuged again to remove any remaining aqueous phase. Solvent was evaporated first at water bath $\left(80^{\circ} \mathrm{C}\right)$ and then at $103-105^{\circ} \mathrm{C}$ in an oven. Total lipid was quantified by weighing the dried extract and reported as $\mathrm{mg} / \mathrm{mL}$ of brew. 
Total lipid content of R\&G coffee

Coffee oil was Soxhlet extracted according to Araújo and Sandi [11]. For this purpose, $20 \mathrm{~g}$ of ground coffee (particle size $\leq$ $500 \mu \mathrm{m})$ were extracted using $n$-hexane $(250 \mathrm{~mL})$ for $16 \mathrm{~h}$. Successively, solvent was removed by rotary evaporation (BUCHI, R-210, Switzerland) at $30^{\circ} \mathrm{C}$ followed by residual solvent evaporation in an oven (103-105 $\left.{ }^{\circ} \mathrm{C}\right)$. The weight of coffee oil was reported as $\mathrm{g} / 100 \mathrm{~g}$ of ground coffee in wet and dry basis.

Diterpenes extraction from EC

Diterpenes in coffee brews were measured according to a previously optimized and validated methodology described by Moeenfard et al. [27]. Briefly, $2.5 \mathrm{~mL}$ of heated brew $\left(60^{\circ} \mathrm{C}\right)$ along with $2.5 \mathrm{~mL}$ of distilled water were directly saponified with $3.0 \mathrm{~g}$ of potassium hydroxide in a water bath $\left(80^{\circ} \mathrm{C}-60 \mathrm{~min}\right)$. The solution was then subjected to two sequential extractions using diethyl ether followed by clean-up with $5.0 \mathrm{~mL}$ of $2 \mathrm{M} \mathrm{NaCl}$ solution. The clean organic phase was brought to dryness under $\mathrm{N}_{2}$ stream and kept at $-22{ }^{\circ} \mathrm{C}$ until analysis using HPLC-DAD. Data were reported as $\mathrm{mg} / \mathrm{L}$ and $\mathrm{mg}$ per cup.

Diterpenes extraction from R\&G coffee

The previously described method [27] was modified regarding potassium hydroxide content (1, 3 or $5 \mathrm{~g})$ and successive extraction using diethyl ether (2, 3 or 4 steps), to improve saponification and extraction efficiency of diterpenes from ground coffee. The best conditions for extracting diterpenes from R\&G coffee was achieved by direct saponification of $200 \mathrm{mg} R \& \mathrm{G}$ Arabica coffee (particle size $\leq 300 \mu \mathrm{m})$ in $7.5 \mathrm{~mL}$ of methanol/water solution $(2: 1 \mathrm{v} / \mathrm{v})$ with $3.0 \mathrm{~g}$ of potassium hydroxide powder $\left(80^{\circ} \mathrm{C}-60 \mathrm{~min}\right)$. The saponified solution was subjected to liquid-liquid extraction using diethyl ether (repeated 4 times) and centrifugation (4000 rpm, $10 \mathrm{~min}$ ). Combined ether phases were washed with $5.0 \mathrm{~mL}$ of $2 \mathrm{M} \mathrm{NaCl}$ solution and taken to dryness under $\mathrm{N}_{2}$ stream. Dried extracts were stored at $-22{ }^{\circ} \mathrm{C}$ until analysis and diterpene content was expressed after applying the dilution factor as mg per $100 \mathrm{~g}$ of R\&G Arabica coffee.

HPLC-DAD analysis

HPLC analysis was performed in a Merck Hitachi Elite LaChrom (Tokyo, Japan) system equipped with a quaternary pump (L2130), an L-2200 autosampler and a L-2455 UV/vis spectrophotometry diode array detector. Separation was achieved using a Purospher STAR LichroCART RP 18 end-capped $(250 \times 4 \mathrm{~mm}, 5 \mu \mathrm{m})$ column attached to a guard column $(4 \times 4 \mathrm{~mm}, 5 \mu \mathrm{m})$ of the same kind. The detection wavelengths were $225 \mathrm{~nm}$ for cafestol and $290 \mathrm{~nm}$ for kahweol. EZChrom Elite 3.1.6 software was used for data acquisition and analysis.

Before chromatographic analysis, the dried extracts were made up to $2.5 \mathrm{~mL}$ (ECs) or $10 \mathrm{~mL}$ (R\&G Arabica coffee) with acetonitrile. Twenty microliters of the reconstituted samples were injected after filtration $(0.45 \mu \mathrm{m}$ polytetrafluoroethylene membranes (PTFE), VWR, USA). Mobile phase was acetonitrile/water $(55 / 45, \mathrm{v} / \mathrm{v})$ with an isocratic flow rate of $0.8 \mathrm{~mL} / \mathrm{min}$ [27]. Target compounds were identified by comparing spectra and retention times of reference standard solutions. Quantitative 
analysis was performed using external standard calibration curves by plotting the peak area vs. the corresponding concentrations.

Method validation

Calibration curves for cafestol and kahweol were plotted after injection of nine standards in the range of 2-200 mg/L. Validation parameters, including precision (expressed as coefficient of variation, \%CV), accuracy (expressed as percentage of recovery) and limits of detection and quantification were determined with regards to R\&G Arabica coffee, as well as standard EC. Method and instrumental precisions were obtained through the coefficient of variation of repeated analysis at intra-day and inter-day conditions, respectively. Intra-day precision (repeatability) was evaluated through six replicate analyses in the same day. In the inter-day variation studies (reproducibility), an extract of the same sample was analyzed three times on three consecutive days. Method accuracy was evaluated by spiking both matrices (EC and R\&G coffee) with cafestol and kahweol standards (25 and $50 \%$ of the initial concentration of diterpenes, in duplicate), before the extraction procedure and then the average recovery ( $\%)$ was reported as the mean ratio between the obtained and the expected concentrations of diterpenes in fortified samples. The limits of detection (LOD) and of quantification (LOQ) were calculated based on a signal to noise ratio of three ( $\mathrm{S} / \mathrm{N}=3)$ and ten $(\mathrm{S} / \mathrm{N}=10)$, respectively.

Statistical analysis

A two-way ANOVA analysis was performed to evaluate the impact of both the successive extractions with diethyl ether and the amount of potassium hydroxide on extraction of diterpenes from R\&G Arabica coffee. Differences were considered significant when $p \leq 0.05$. Differences between different levels of each variable in ECs preparation were evaluated by ANOVAone way at four replications with a level of significance of $95 \%$. Data was reported as means \pm standard deviations. All statistical analysis was carried out by Matlab 7.12.0 software. Figures were plotted by means of Matlab 7.12.0, Excel (2010) and Minitab 16 software (2009).

\section{Results and discussion}

Optimization of diterpenes extraction from $R \& G$ coffee

Since R\&G coffee contained appreciable amounts of diterpenes, the previously optimized method [27] was modified in order to increase diterpenes extraction efficiency from coffee beans. Successive extractions by diethyl ether and different amounts of potassium hydroxide for saponification procedure were tested and compared by two-way ANOVA analysis at a significance level of $95 \%$. Table 1 presents the analysis of variance in detail. As can be clearly seen in Fig. 2, both compounds showed similar behavior and the best saponification efficiency was achieved with $3.0 \mathrm{~g}$ of potassium hydroxide. On the other hand, using $5.0 \mathrm{~g}$ of potassium hydroxide caused a significant decrease in diterpenes content ( $p \leq 0.05)$, probably due to decomposition of these compounds in a highly basic solution. Regarding successive extractions using diethyl ether, as depicted in Fig. 2, the 
most concentrated extract was obtained by four sequential extractions of diterpenes using diethyl ether. Since high recovery was obtained for both compounds, four sequential extractions were found to be adequate for diterpenes extraction. Therefore the optimal conditions for extraction of diterpenes from $R \& G$ coffee was achieved with $3.0 \mathrm{~g}$ of potassium hydroxide combined with four sequential extractions and these conditions were fixed for the analytical method.

The average contents of diterpenes and lipid in the investigated Arabica coffee are presented in details in Table 2. The average amounts of cafestol and kahweol in the analyzed Arabica been were $467.62 \pm 20.02$ and $638.04 \pm 33.64 \mathrm{mg} / 100 \mathrm{~g}$ of sample, respectively. Regarding the coffee oil, our findings were in the range of $14.76 \pm 0.13$ (wet basis) to $15.12 \pm 0.13 \mathrm{~g} / 100 \mathrm{~g}$ of R\&G coffee (dry weight). The oil content observed in the present study was consistent with previous data reported for Arabica coffee [11] while diterpenes content were higher than those reported previously [11]. According to Kitzberger et al. [8], cafestol content of Arabica coffee from different cultivars (Catuaí, IPR100, IPR102, IPR106) varied from 221 to 604 $\mathrm{mg} / 100 \mathrm{~g}$ and the kahweol content ranged from 371 to $980 \mathrm{mg} / 100 \mathrm{~g}$ of roasted beans [8].

Validation of the analytical method

The coefficients of determination $\left(R^{2}\right)$ of 0.999 , both for cafestol and kahweol, clearly demonstrate a good linearity in the range of 2-200 mg/L (ECs) and 10-1000 mg/100 g (R\&G coffee). Acceptable repeatability was obtained between replicate analyses in ECs, with coefficients of variation of $8.55 \%$ (cafestol) and $8.60 \%$ (kahweol). With regard to R\&G Arabica coffee, repeatability of $1.57 \%$ was achieved both for cafestol and kahweol. Regarding ECs, the reproducibility were $0.85 \%$ (cafestol) and $0.80 \%$ (kahweol) while reproducibility of cafestol and kahweol in R\&G Arabica coffee was $0.48 \%$ and $0.67 \%$, respectively. High recoveries were obtained in ECs (85\% for cafestol and 86\% for kahweol) and R\&G Arabica coffee (94\% for cafestol and $96 \%$ for kahweol). The detection limits for the analyzed samples were $0.09 \mathrm{mg} / \mathrm{L}$ for cafestol and $0.07 \mathrm{mg} / \mathrm{L}$ for kahweol in ECs. Regarding R\&G coffee, limit of detections were 0.45 (cafestol) and $0.35 \mathrm{mg} / 100 \mathrm{~g}$ (kahweol). Analysis of diterpenes with HPLC-DAD resulted in quantification limits of 0.29 and $0.24 \mathrm{mg} / \mathrm{L}$ for cafestol and kahweol of ECs, respectively. Values of $1.45 \mathrm{mg} / 100 \mathrm{~g}$ for cafestol and $1.20 \mathrm{mg} / 100 \mathrm{~g}$ for kahweol were obtained for limit of quantification in R\&G Arabica coffee. The validation parameters for cafestol and kahweol are listed in Table 3.

Effect of preparation parameters on diterpenes content of ECs

To investigate diterpenes extraction during espresso brewing, the following technological factors: coffee amounts, water quantity, extraction time, particle size, water temperature as well as water pressure, were taken into account. This study was conducted by varying one-at-a-time parameter. Therefore for each variable studied, the other parameters used for preparation of EC were the conditions used for standard EC as follow: fine R\&G coffee $(7.5 \mathrm{~g})$, water quantity $(40 \mathrm{~mL})$, extraction time $(21 \mathrm{~s})$, water temperature $\left(90^{\circ} \mathrm{C}\right)$ water pressure $(9 \mathrm{bar})$, with an exception regarding parameter of particle size, where the time of extraction was 35,21 and $10 \mathrm{~s}$ for very fine, fine and coarse ground coffee. 


\section{Effect of $R \& G$ coffee amount}

Table 4 presents the results of the diterpenes (cafestol and kahweol) as well as the total lipid content, expressed either in concentration or in mass of compound per cup basis. Variability was observed within different amounts of R\&G coffee. The mean total values of cafestol and kahweol were $1.28,1.62,1.63$ and $1.70 \mathrm{mg} / 40 \mathrm{~mL}$ for $6.5,7.5,8.5$ and $9.5 \mathrm{~g}$ of R\&G Arabica coffee, respectively. The increase in total diterpenes content in analyzed samples with increasing the amounts of coffee from $7.5 \mathrm{~g}$ to $9.5 \mathrm{~g}$ was actually relative and not significant $(p \geq 0.05)$. The porosity of coffee bed influences by quantity of coffee powder and tamping [28]. At higher amount of R\&G coffee ( 8.5 and $9.5 \mathrm{~g}$ ), probably, excessive amount of coffee resulted in over-compaction [29] and disturbed the percolation of lipid droplets and subsequently diterpenes extracted to lesser extents into the brews. Positive correlation between diterpenes content and amount of coffee in the present study are consistent with a previously published paper [21].

Concerning lipids, the total content seems to have increased along with coffee amounts up to $7.5 \mathrm{~g}$ although differences were not statistically significant at higher amounts of ground coffee $(p \geq 0.05)$. Indeed, compact coffee bed with limited space did not allow proper water flow through the ground coffee. Significant variation in the lipid content of ECs prepared using different coffee/water ratio was observed in the literature [20], although difference among 7.5 and $8.5 \mathrm{~g}$ of R\&G coffee was neither remarkable nor linear [20].

\section{Effect of water quantity}

Obtained results indicated that water quantity significantly affected the level of diterpenes in ECs (Table 4). Total diterpenes concentrations of ECs prepared with different water quantity were in the range of $29.29 \pm 1.39$ (corresponding to $1.46 \mathrm{mg} / 50$ $\mathrm{mL}$ ) to $55.78 \pm 0.83 \mathrm{mg} / \mathrm{L}$ (corresponding to $1.67 \mathrm{mg} / 30 \mathrm{~mL}$ ). In espresso brewing techniques, one of the factors that control the coffee cake porosity and consequently the water/coffee contact time is tamping [28]. In this experiment, cake compression in porta-filter varied depending on each cup size which resulted in ECs with different volumes but almost similar percolation time ( $21 \pm 3 \mathrm{~s})$. Different compacting force used for compression of ground coffee generated coffee bed with different porosity which probably affect the water passage through the cake and led to various diterpenes content. Besides that, at a constant coffee amount and percolation time, $R \& G$ coffee stays in contact with more hot water, increasing the extraction yield. Buchmann et al. [21] reported higher cafestol content in brews with higher cup size however the correlation between the extraction yield and the amount of water was non-linear.

The concentration of lipids in the brews showed almost similar behavior as diterpenes and varied from $2.02 \pm 0.14 \mathrm{mg} / \mathrm{mL}$ to $2.95 \pm 0.10 \mathrm{mg} / \mathrm{mL}$ in ECs brewed with 50 and $30 \mathrm{~mL}$ of water, respectively. On $\mathrm{mg} / \mathrm{mL}$ basis, lipids were mainly extracted in those coffees with lower volume ( 30 and $40 \mathrm{~mL}$ ), but as will be discussed later, amount per serving and extraction efficiency is attributed to the cup size so different oil extraction yield profiles were found. It should be stressed out that the chemical composition of EC may affected by the water quality [5] as presences of particular compounds such as carbunates resulted in bitter and flat coffee brew [30]. Besides that, although coffee brews were identified with a certain degree of acidity but coffee brews prepared from distilled water were found to be exessively sour and astringent [30]. 


\section{Effect of grinding grade}

Probably one of the most important steps in preparing a great cup of EC is the grinding process. In order to prepare a high quality EC, a range of particle size distribution from coarse to very fine ground is required [22]. The water flow through the coffee cake is provided by the coarse ground which results in the appropriate extraction of compounds from the finer ground to the surrounding water [22]. Particles size distributions for brewing EC are shown in Fig. 1. As it can be clearly seen, all types of grinds contain a high percentage of medium sized particles ( 250 to $350 \mu \mathrm{m}$ ). It was observed that brewed coffee using very fine ground coffee extracted the highest amount of total diterpenes $(58.86 \pm 0.75 \mathrm{mg} / \mathrm{L})$ followed by fine $(40.39 \pm 3.97 \mathrm{mg} / \mathrm{L})$ and coarse particles (37.96 $\pm 3.27 \mathrm{mg} / \mathrm{L}$ ) (Table 4). During grinding, extraction surface area increases, so substances are released and dissolved more easily and quickly upon contact with water [31]. Since very fine grinds provide larger surface area, more diterpenes can be extracted along with reduction in particle size.

The percolation time is known to be dependent on the particle size. The finer the grinds, the more time is required to produce a specific volume of brew. Since percolation time for finer ground coffee $(35 \pm 3 \mathrm{~s})$ was higher than for coarse particles $(10 \pm 3$ s), an elevation in diterpenes concentration may be partially attributed to the higher extraction time.

As shown in Table 4, a similar behavior was observed for the lipid content. Higher amounts were obtained from very fine ground coffee $(2.66 \pm 0.10 \mathrm{mg} / \mathrm{mL})$. Higher amounts of extracted compounds from fine particles than coarse ones have been extensively reported [21, 22]. Andueza, de Peña and Cid [22] indicated that higher lipid content was extracted from very fine particles of $R \& G$ coffee while a lesser amount of lipids was obtained from coarse particles. They also showed an inverse correlation between particle size and the extraction of solids and soluble compounds. A similar pattern was observed by Buchmann et al. [21] who claimed that EC prepared by finely grounds contained higher cafestol content in comparison to medium and coarse particles. However, there was apparently a disagreement with the results of lipid content reported by Sehat and Niedwetzki [32] who reported less extraction efficiency of lipids from finer coffee powder than from more coarsely grounds.

\section{Effect of percolation time}

ECs prepared by $7.5 \mathrm{~g}$ of finely ground Arabica coffee were compared in terms of percolation times (Table 4). The best time range for extraction is $25-30 \mathrm{~s}$ because extractions shorter than $15 \mathrm{~s}$ produce a weak beverage and longer than $30 \mathrm{~s}$, produced beverage that have a poor flavor and harsh tasting [2]. The ground coffee was placed in the porta-filter and was manually tamped with espresso tamper using several forces to distribute the coffee evenly and to keep the percolation time in three different values through adjusting the porosity. In the present experiment, extraction times of $10 \pm 3,21 \pm 3$ and $30 \pm 3 \mathrm{~s}$ were selected for the shortest, medium and longest percolation time and were applied until the volume in the cup met $40 \pm 2 \mathrm{~mL}$. Variation in time of extraction induced changes on the diterpenes and lipid contents of ECs. Long contact time between water and coffee grounds allows the water to solubilize extractable materials, diterpenes and lipids more efficiently. Concerning diterpenes content, difference at the beginning of extraction (10 and $21 \mathrm{~s})$ was not remarkable $(p \geq 0.05)$. This may be due to this fact that diterpenes were mainly extracted at the beginning of the brewing process. By continuing the extraction to $30 \mathrm{~s}$, remaining diterpenes were leached into the brew and made the diterpenes concentration slightly higher. It is reported that longer 
percolation time yields a higher percentage of less soluble substances in the beverage [3].

The extraction time imposed during the experiments resulted in ECs with various lipid contents ranging from $2.19 \pm 0.07$ to $2.66 \pm 0.14 \mathrm{mg} / \mathrm{mL}$ obtained from 10 and $30 \mathrm{~s}$ brewing time, respectively. Caprioli et al. [24] evaluated the chemical composition of ECs at different stages of brewing. Concerning lipids, the concentration were higher at the first $10 \mathrm{~s}$. Afterwards, in the last time sections (31-40 s), extracted lipids decreased as almost no lipids was extracted to the brew during this period of time.

\section{Effect of water temperature}

Upon comparison of the diterpenes at different temperatures a remarkable increase in diterpenes content was observed from 70 ${ }^{\circ} \mathrm{C}(30.77 \pm 0.80 \mathrm{mg} / \mathrm{L})$ to $90{ }^{\circ} \mathrm{C}(40.39 \pm 3.97 \mathrm{mg} / \mathrm{L})$ (Table 4). Although higher temperature led to higher diterpenes, difference among 80 and $90{ }^{\circ} \mathrm{C}$ was not statistically significant $(p \geq 0.05)$. The influence of water temperature on physicochemical and sensorial properties of ECs has been already documented [23] but few authors studied the diterpenes concentration of ECs as affected by temperature [21]. Buchmann et al. [21] found three times higher cafestol content in fresh brew (made without pressure) prepared at $110^{\circ} \mathrm{C}$ in comparison to $80^{\circ} \mathrm{C}$. According to Buchmann et al. [21] effect of water temperature on cafestol content of EC was insignificant. Temperature is mainly attributed to extraction parameters like total solids and concentration [22]. Nevertheless, the hot water melts also the lipids that have been diffused to the surface after roasting and leads to formation of a fine lipid emulsion [33]. Increase in the solubility of lipidic compounds and thermodynamic properties of the extraction were mentioned as possible reasons for this elevation. According to literature [34] due to changes in water polarity (close to alcohol) under certain temperature and applied pressure, a wide range of medium to low polarity compounds may dissolve in water. Indeed, at higher temperature the properties of water for solubilizing compounds improve. Improvement in the solubility and mass transfer effects as well as an increased disruption of surface equilibrium are accounted as factors which involve in higher extraction efficiency of compounds through pressurized hot water extraction (PHWE) [34].

Changes in temperature also correspond to significant differences in lipid content. The average contents of total lipid were in the range of $1.60-2.62 \mathrm{mg} / \mathrm{mL}$ of EC. These results are consistent with the conclusion taken from previously published literature [23] where ECs showed a remarkable increase in total lipid along with increasing in temperature from $88{ }^{\circ} \mathrm{C}$ to 98 ${ }^{\circ} \mathrm{C}$. Similar trend was observed by Masella et al. [35], where higher water temperature led to a significant increase in lipid content of Caffè Firenze which is a new espresso brewing techniques and has been developed recently. The values ranged 0.61 to $1.29 \mathrm{mg}$ lipid/mL was reported by Masella et al. [35] for this new EC.

\section{Effect of water pressure}

Transformation of pressure energy to kinetic energy and subsequently into surface-type potential energy during the extraction procedure yields transfer of small solid particles and oil droplets into the cup [3]. For preparing the EC samples, Arabica coffee was extracted at constant temperature and at different pressures (7, 9, 11 and 14 bar). As experiments were carried out using an EC machine equipped with an electric pump, isobaric conditions could be maintained during extraction. With regard to the effects of water pressure upon diterpene concentration, increasing the pressure from 7 to 11 bar led to richer extracts in terms of diterpenes $(p \leq 0.05)$ while a negative effect was observed at 14 bar and resulted in reduced amount of diterpenes. Maximum 
diterpenes concentration was achieved for pressure of 11 bar which was higher than the obtained values for the other pressures. Cafestol content of ECs brewed under 7, 9 and 14 bar indicated no remarkable variations $(p \geq 0.05)$. Concerning kahweol, ECs prepared using pressure of 9 and 11 bar, showed higher values with respect to other pressures considered (Table 4).

Total lipids content changed along with pressure but these changes were not linear. Different pressures resulted in ECs with lipid concentration ranging from $1.59 \pm 0.10$ ( 7 bar) to $2.62 \pm 0.13 \mathrm{mg} / \mathrm{mL}$ ( 9 bar). According to the literatures $[6,25,35]$ the concentration of lipid in the ECs can vary in accordance to applied pressure. Entrance of water into area of matrices due to the presence of pressure may assist extraction of particular compounds which are trapped in the matrix pores [34]. According to Andueza et al. [25] increasing the water pressure from 7 to 9 bar caused significant elevation in total lipid content of analyzed ECs. However, by continuing the pressure increasing to 11 bar, ECs indicated less lipid concentration. This result could be explained by nonlinear correlation between average flow and pressure around the pressure of 9 bar which is despite Darcy's law [25]. Parenti et al. [6] indicated that with the same batch of roasted coffee, total lipids concentration extracted from ECs prepared with an traditional bar machine was lower than capsules brewed using espresso system or hyper espresso method. The infusion temperature and pressure were recognized as prominent parameters for this diversity. Higher pressures and temperatures caused richer extracts in terms of lipid contents [6]. Unlike our finding, lipid content was not affected by pressure values (15 and 20 bar) in Caffè Firenze [35].

Diterpenes and total lipid extraction efficiency

As was mentioned earlier, by varying the preparation parameters, different ECs might be prepared in terms of diterpenes and lipid content. Several technological parameters including coffee/water ratio, roasting grade, grinding degree and water temperature may affect the extraction yield [29]. The different ECs under study were also evaluated with regards to diterpenes extraction efficiency and values ranging from 1.4 to $2.9 \%$ were obtained both for cafestol and kahweol (Fig. 3). In general, increasing serving size $(60 \mathrm{~mL})$ and extraction time $(30 \mathrm{~s})$ as well as using finer particles yielded a cup of EC richer in terms of diterpenes.

Under the experimental conditions, the highest extraction efficiency values both for cafestol (2.8\%) and kahweol (2.9\%) were acquired from ECs prepared using very fine particles with respect to extraction efficiencies described for other ECs (ranging from 1.5 to $2.5 \%$ ). In view of the fact that finer particles have more surface area, the physical availability of diterpenes within the R\&G coffee increases and more diterpenes are transferred into the surrounding water and the lesser is the amount left in the spent coffee grounds.

Concerning the volume of coffee beverage although diterpenes concentration in $60 \mathrm{~mL}$ of EC (36.28 $\pm 3.18 \mathrm{mg} / \mathrm{L})$ was less than $30 \mathrm{~mL}(55.78 \pm 0.83 \mathrm{mg} / \mathrm{L})$, but since extraction is dose dependent, their diterpenes extraction efficiencies would be different. The higher values of cafestol (2.6\%) and kahweol extraction efficiency (2.7\%) were achieved in $60 \mathrm{~mL}$ of EC with respect to $30 \mathrm{~mL}$ with diterpenes extraction yield of $1.9 \%$ for cafestol and $2.2 \%$ for kahweol.

Longer percolation time (30 s) presented extraction efficiency of $2.3 \%$ (cafestol) and $2.6 \%$ (kahweol). These results is proposed to be due to the higher contact time between hot water and ground coffee caused releasing more compound to the surrounding water.

The lower diterpene extraction efficiency was revealed in EC brewed at $70^{\circ} \mathrm{C}$ with values around 1.4 and $1.5 \%$ for cafestol 
and kahweol, respectively. The prominent factor which affects the extraction efficiency through pressurized hot water extraction is temperature. Indeed, at elevated temperature, physical properties of water will positively influence to increase extraction yield. High diffusion, low viscosity and low surface tension are some of the advantageous of application of hot water for extraction [34] which probably are not supplied at lower temperature in order to improve extraction efficiency.

Cafestol extraction yields for different coffee brews were summarized previously by Zhang et al. [26] ranging from $2.0 \%$ to $8.0 \%$ for boiled, French, mocha and Turkish coffee.

The content of lipid in analyzed EC varied from 1.59 to $2.95 \mathrm{mg} / \mathrm{mL}$. Oil extraction yields were in the range of 5.0-11.0\% with an average level of 7.0-9.0\% (Table 4). This means that around 7.0-9.0\% of R\&G coffee lipid was transferred to the coffee beverage during espresso brewing technique. Coffee brews are generally poor in lipids, however, on a normalized g/L basis espresso brewing techniques deliver more lipids than other brewing procedures [36] which is probably due to the extraction under high pressure and temperature [36]. Our findings were in accordance with the average lipid content of $2.26 \mathrm{mg} / \mathrm{mL}$ for EC prepared with Arabica coffee previously reported by Ratnayake et al. [36]. However, the lipid contents of ECs recorded in the present work were less than those reported by other authors [22, 23, 25]. Regarding lipid extraction efficiency, Sehat and Niedwetzki [32] suggested lipid extraction yield of $2.5 \%$ for EC which was significantly lower than those found in the present study.

\section{Conclusions}

The effect of brewing conditions on the diterpenes and lipid profile of espresso coffee (EC) and their extraction efficiencies from roasted and ground (R\&G) Arabica coffee were comprehensively investigated. The influence of preparation parameters, namely water quantity, amount of ground coffee, grinding size, percolation time, water temperature and pressure on cafestol and kahweol content of ECs were studied in the present experiment. The operating conditions that provide the highest diterpenes concentration per cup of coffee were brewing espresso coffee with very fine particles or with bigger cup size. Generally speaking, by varying the preparation parameters, we could reduce the total diterpenes from $58.86 \pm 0.75 \mathrm{mg} / \mathrm{L}(2.35 \mathrm{mg} / 40 \mathrm{~mL}$, brewed with very fine particles) to $30.77 \pm 0.80 \mathrm{mg} / \mathrm{L}\left(1.23 \mathrm{mg} / 40 \mathrm{~mL}\right.$, brewed at $\left.70{ }^{\circ} \mathrm{C}\right)$. Consequently, different operation conditions seem to play an important role on diterpene extraction efficiency. Overall, only $1.4 \%$ of the cafestol and $1.5 \%$ of kahweol present in the R\&G Arabica coffee are effectively extracted to the $\mathrm{EC}$ brewed under $70{ }^{\circ} \mathrm{C}$ while EC prepared with very fine particles revealed higher extraction efficiencies for cafestol (2.8\%) and kahweol (2.9\%).

The role of coffee diterpenes on human health is still far from established and therefore the doubt still remains about the health effects of increasing or reducing coffee diterpenes levels. Overall, this study clearly shows that changes in parameters of coffee brew preparation may be used to modulate EC diterpenes content. This data may also prove useful when assessing diterpenes exposure through coffee intake in a population.

\section{Acknowledgment}

This work was funded by FEDER funds through the Operational Programme for Competitiveness Factors - COMPETE, ON.2 - O Novo Norte - North Portugal Regional Operational Program and National Funds through FCT - Foundation for Science 
and Technology under the projects: PEst-C/EQB/UI0511, NORTE-07-0124-FEDER-000025 - RL2_ Environment \& Health and SFRH/BD/79318/2011.

\section{References}

1. Illy A, Viani R (2005) Espresso coffee: the science of quality (2 ed). Elsevier Academic Press, UK

2. Illy A (2005) Quality, In: A Illy, R Viani (ed) Espresso coffee: The science of quality, 2 ed. Elsevier Academic Press, USA

3. Petracco M (2001) Technology IV: Beverage preparation, brewing trends for the new millennium, In: R J Clarke and O G Vitzthum (ed) Coffee: Recent developments. Blackwell Science, UK

4. Nunes F M, Coimbra M A, Duarte A C, Delgadillo I (1997) Foamability, foam stability, and chemical composition of espresso coffee as affected by the degree of roast. J Agr Food Chem 45: 3238-3243

5. Navarini L, Rivetti D (2010) Water quality for Espresso coffee. Food Chem 122: 424-428

6. Parenti A, Guerrini L, Masella P, Spinelli S, Calamai L, Spugnoli P (2014) Comparison of espresso coffee brewing techniques. J Food Eng 121: 112-117

7. Scholz M B S, Pagiatto N F, Kitzberger C S G, Pereira L F P, Davrieux F, Charmetant P, Leroy T (2014) Validation of near-infrared spectroscopy for the quantification of cafestol and kahweol in green coffee. Food Res Int 61: 176-182

8. Kitzberger C S, Scholz M B, Pereira L F, Vieira L G, Sera T, Silva J B J D , Benassi M T (2013) Diterpenes in green and roasted coffee of Coffea arabica cultivars growing in the same edapho-climatic conditions. J Food Compos Anal 30: $52-57$

9. Kölling-Speer I, Strohschneider S, Speer K (1999) Determination of free diterpenes in green and roasted coffees. J High Resolut Chrom 22(1): 43-46

10. Speer K, Kölling-Speer I (2006) The lipid fraction of the coffee bean. Braz J Plant Physiol 18(1): 201-216

11. Araújo J M A, Sandi D (2006) Extraction of coffee diterpenes and coffee oil using supercritical carbon dioxide. Food Chem 101: 1087-1094

12. Urgert R, Essed N, van der Weg G, Kosmeijer-Schuil T G, Katan M B (1997) Separate effects of the coffee diterpenes cafestol and kahweol on serum lipids and liver aminotransferases. Am J Clin Nutr 65: 519-524

13. Boekschoten M V, Evert G Schouten E G, Katan M B (2004) Coffee bean extracts rich and poor in kahweol both give rise to elevation of liver enzymes in healthy volunteers. Nutr J 3(7)

14. Lee K J, Jeong H G (2007) Protective effects of kahweol and cafestol against hydrogen peroxide-induced oxidative stress and DNA damage. Toxicol Lett 173: 80-87

15. Cavin C, Holzhäuser D, Scharf G, Constable A, Huber A A, Schilter B (2002) Cafestol and kahweol, two coffee specific diterpenes with anticarcinogenic activity. Food Chem Toxicol 40: 1155-1163

16. Cárdenas C, Quesada A R, Medina M A (2011) Anti-Angiogenic and anti-inflammatory properties of kahweol, a coffee diterpene. PLoS ONE 6(8)

17. Wang S, Yoon Y C, Sung M J, Hur H J, Park J H (2012) Antiangiogenic properties of cafestol, a coffee diterpene, in human umbilical vein endothelial cells. Biochem Biophys Res Commun 421, 567-571

18. Cavin C, Holzhäuser D, Constable A, Huggett A C, Schilter B (1998) The coffee-specific diterpenes cafestol and kahweol protect against aflatoxin B1-induced genotoxicity through a dual mechanism. Carcinogenesis 19(8): 1369-1375 
19. Gloess A N, Schönbächler B, Klopprogge B, D‘Ambrosio L, Chatelain K, Bongartz A, Strittmatter A, Rast M, Yeretzian C (2013) Comparison of nine common coffee extraction methods: instrumental and sensory analysis. Eur Food Res Technol 236: $607-627$

20. Andueza S, Vila M A, de Pena M P, Cid C (2007) Influence of coffee/water ratio on the final quality of espresso coffee. J Sci Food Agr 87: 586-592

21. Buchmann S, Zahm A, Kölling-Speer I, Speer K (2009) Lipids in coffee brews, impact of grind size, water temperature, and coffee/water ratio on cafestol and the carboxylic acid-5-hydroxytryptamides. Euro Food Chemistry XV, Copenhagen Denmark.

22. Andueza S, de Peña M P, Cid C (2003) Chemical and sensorial characteristics of espresso coffee as affected by grinding and torrefacto roast. J Agr Food Chem 51: 7034-7039

23. Andueza S, Maeztu L, Pascual L, Ibáñez C, de Peña M P, Cid C (2003) Influence of extraction temperature on the final quality of espresso coffee. J Sci Food Agr 83: 240-248

24. Caprioli G, Cortese M, Cristalli G, Maggi F, Odello L, Ricciutelli M, Sagratini G, Sirocchi V, Tomassoni G, Vittori S (2012) Optimization of espresso machine parameters through the analysis of coffee odorants by HS-SPME-GC/MS. Food Chem 135: 1127-1133

25. Andueza S, Maeztu L, de Peña M P, Dean B, Bello J, Cid C (2002) Influence of water pressure on the final quality of arabica espresso coffee, application of multivariate analysis. J Agr Food Chem 50: 7426-7431

26. Zhang C, Linforth R, Fisk I D (2012) Cafestol extraction yield from different coffee brew mechanisms. Food Res Int 49: 27-31

27. Moeenfard M, Silva J A, Borges N, Santos A, Alves A. Quantification of diterpenes and their palmitate esters in coffee brews by HPLC-DAD. Int J Food Prop, DOI: 10.1080/10942912.2014.933351

28. Illy E, Navarini L (2011) Neglected Food Bubbles: The Espresso Coffee Foam. Food Biophys 6(3): 335-348

29. Petracco M (2005) The cup, In: A Illy, R Viani (ed) Espresso coffee: The science of quality, 2 ed. Elsevier Academic Press, USA

30. Pangborn R M, Trabue I M, Little A C (1971) Analysis of coffee, tea and artificially flavored drinks prepared from mineralized waters. J Food Sci 36: 355-362.

31. Petracco M (2005) Grinding, In: A Illy, R Viani (ed) Espresso coffee: The science of quality, 2 ed. Elsevier Academic Press, USA

32. Sehat N, Niedwetzki G (1997) Coffee lipids: Aanalysis of diterpene 16-O-methylcafestol as an indicator of admixing of coffee, In: R E McDonald, M M Mossoba, New techniques and applications in lipid analysis. AOCS Press, USA

33. Roth k (2003) Espresso-ein Dreistufenpräparat. Chemie in unserer Zeit 37(3): 215-217

34. Teo C C, Tan S N, Yong J W H, Hew C S, Ong E S (2010) Pressurized hot water extraction (PHWE). J Chromatogr A 1217: 2484-2494

35. Masella P, Guerrini L, Spinelli S, Calamai L, Spugnoli P, lly F, Parenti A (2015) A new espresso brewing method. J Food Eng 146: 204-208

36. Ratnayake W M N, Hollywood R, Grady E, Stavric B (1993) Lipid content and composition of coffee brews prepared by different methods. Food Chem Toxicol 3(4): 263-269 


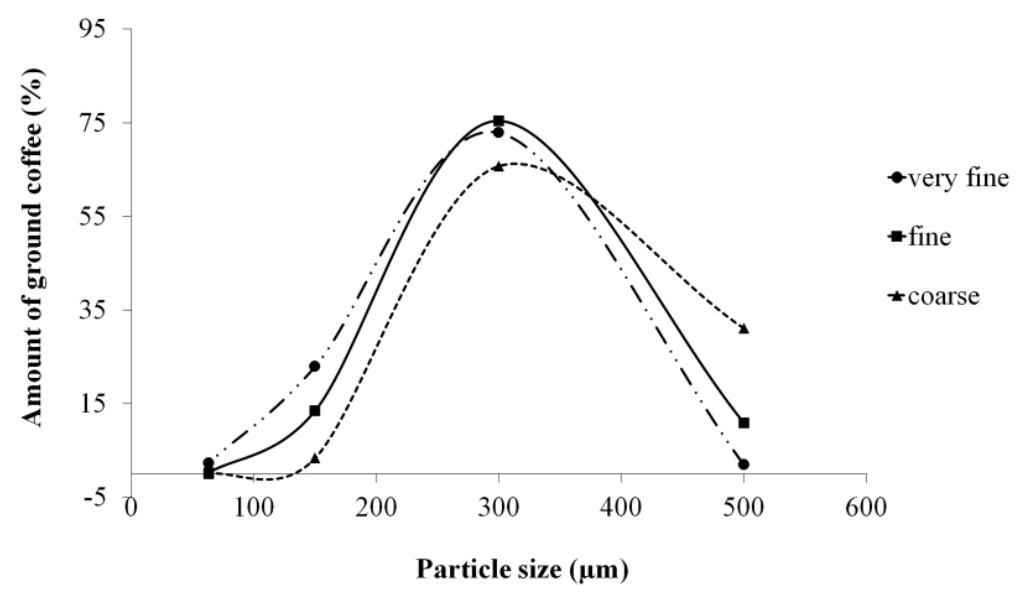

Fig. 1 Particles size distribution of very fine, fine and coarse roasted and ground Arabica coffee 

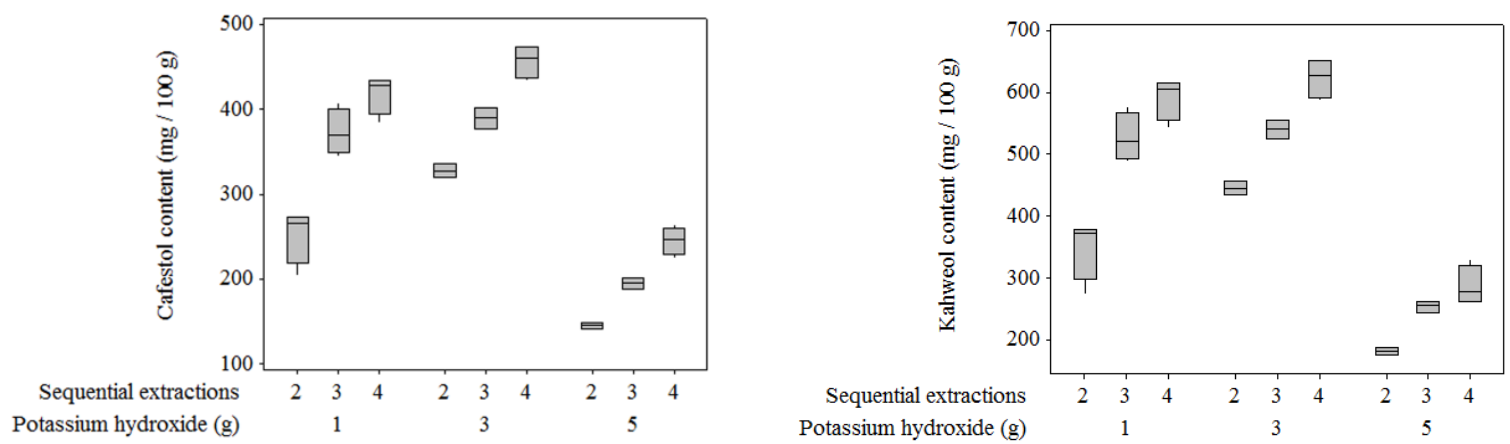

Fig. 2 Boxplot of cafestol and kahweol content (mg/100 g) vs. potassium hydroxide (g) and sequential extractions using diethyl ether in R\&G Arabica coffee. 


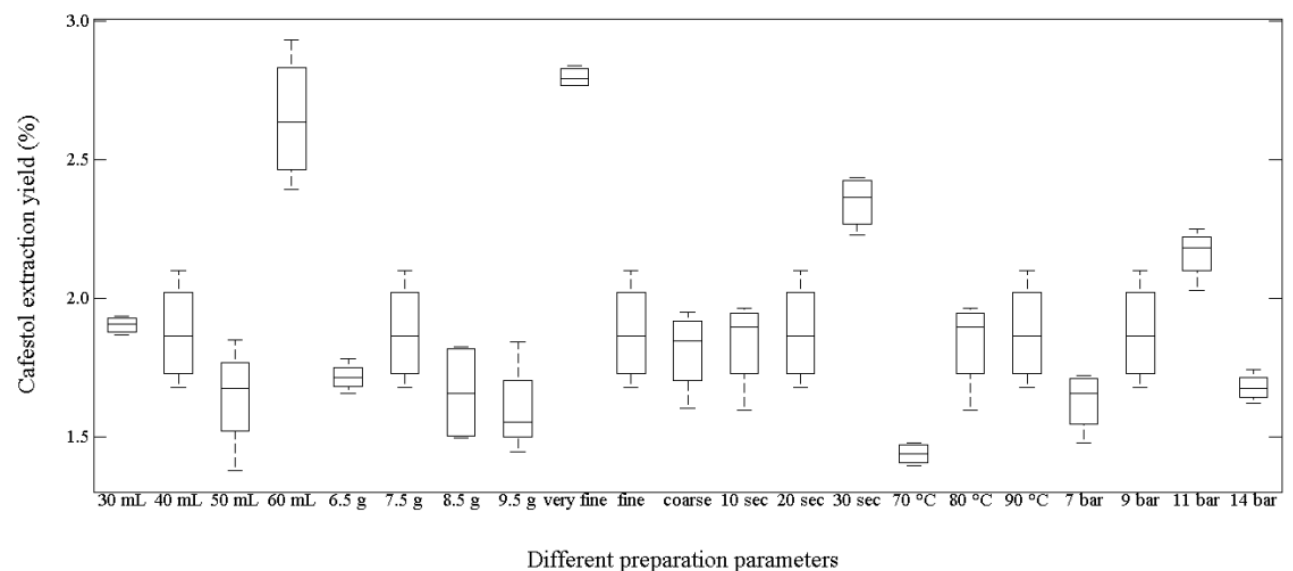

Different preparation parameters

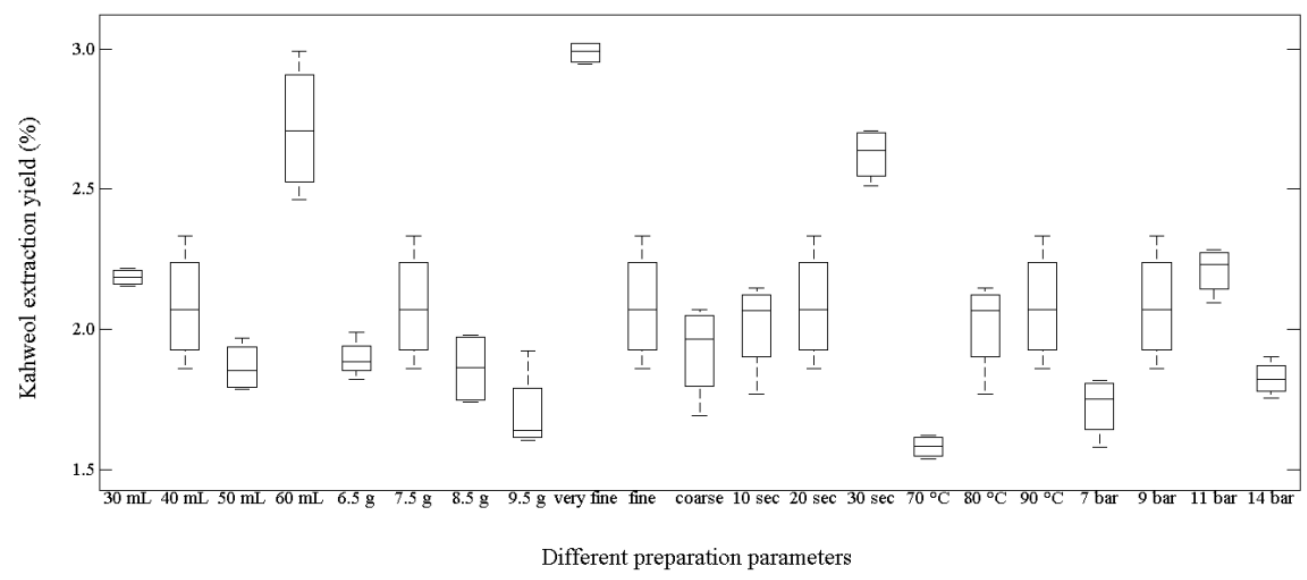

Fig. 3 Cafestol and kahweol extraction yield (\%) in espresso coffee as influence by preparation parameters. Yield= [brew diterpenes concentration $(\mathrm{mg} / \mathrm{L}) \times$ total brew volume $(\mathrm{L})] /[\mathrm{R} \& \mathrm{G}$ diterpenes concentration $(\mathrm{mg} / \mathrm{kg}) \times$ total $R \& G(\mathrm{~kg})] \times 100$, where $R \& G$ is roasted and ground coffee [26]. 
Table 1 Two-way ANOVA analysis of cafestol and kahweol (mg/100 g), vs. potassium hydroxide (g) and sequential extractions using diethyl ether

\begin{tabular}{|c|c|c|c|c|c|c|c|c|c|c|}
\hline \multirow{2}{*}{ Source } & \multirow{2}{*}{ Source $^{a}$} & \multirow{2}{*}{$\begin{array}{l}\text { Degree of } \\
\text { freedom }\end{array}$} & \multicolumn{2}{|c|}{ Sum of squares } & \multicolumn{2}{|c|}{ Mean of square } & \multicolumn{2}{|c|}{ F-ratio } & \multicolumn{2}{|c|}{ P-value } \\
\hline & & & cafestol & kahweol & cafestol & kahweol & cafestol & kahweol & cafestol & kahweol \\
\hline Potassium hydroxide (g) & $\mathrm{X}_{1}$ & 2 & 25472 & 606807.8 & 127086 & 303403.9 & 346.2 & 344.93 & 0 & 0 \\
\hline Sequential extractions & $\mathrm{X}_{2}$ & 2 & 104845 & 190849 & 52422.5 & 95424.5 & 142.81 & 108.48 & 0 & 0 \\
\hline Interaction & $\mathrm{X}_{1} \times \mathrm{X}_{2}$ & 4 & 7007.9 & 22582.9 & 1752 & 5645.7 & 4.77 & 6.42 & 0.004 & 0.0009 \\
\hline Error & & 27 & 9911.4 & 23749.8 & 367.1 & 879.6 & & & & \\
\hline Total & & 35 & 375936 & 843989.5 & & & & & & \\
\hline
\end{tabular}

${ }^{a} \mathrm{X}_{1}=$ Potassium hydroxide $(\mathrm{g}) ; \mathrm{X}_{2}=$ Sequential extractions 
Table 2 Average total lipid and diterpenes content of roasted and ground Arabica coffee

\begin{tabular}{|c|c|c|c|c|c|}
\hline \multirow{2}{*}{ Sample } & \multirow{2}{*}{$\begin{array}{l}\text { Humidity } \\
\text { (\%) }\end{array}$} & \multicolumn{2}{|c|}{$\begin{array}{c}\text { Oil content }^{\mathrm{a}} \\
(\mathrm{g} / 100 \mathrm{~g} \text { of sample) }\end{array}$} & \multicolumn{2}{|c|}{$\begin{array}{c}\text { Diterpenes } \\
(\mathrm{mg} / 100 \mathrm{~g} \text { of sample, } \mathrm{dw})\end{array}$} \\
\hline & & (ww) & (dw) & Cafestol & Kahweol \\
\hline $\begin{array}{l}\text { Roasted Arabica } \\
\text { coffee }\end{array}$ & 2.34 & $14.76 \pm 0.13$ & $15.12 \pm 0.13$ & $467.62 \pm 20.02$ & $638.04 \pm 33.64$ \\
\hline
\end{tabular}

${ }^{a}$ Data were reported as wet weight (ww) and dry weight (dw) 
Table 3 Validation parameters for cafestol and kahweol analysis by HPLC-DAD in espresso coffee and roasted and ground (R\&G) Arabica coffee

\begin{tabular}{|c|c|c|c|c|}
\hline & \multicolumn{2}{|c|}{ R\&G Arabica coffee } & \multicolumn{2}{|c|}{ Espresso coffee } \\
\hline & Cafestol & Kahweol & Cafestol & Kahweol \\
\hline Linearity range & $10-1000 \mathrm{mg} / 100 \mathrm{~g}$ & $10-1000 \mathrm{mg} / 100 \mathrm{~g}$ & $2-200 \mathrm{mg} / \mathrm{L}$ & $2-200 \mathrm{mg} / \mathrm{L}$ \\
\hline$R^{2}(\mathrm{~N}=9)$ & 0.999 & 0.999 & 0.999 & 0.999 \\
\hline Limit of detection ${ }^{\mathrm{a}}$ & $0.45 \mathrm{mg} / 100 \mathrm{~g}$ & $0.35 \mathrm{mg} / 100 \mathrm{~g}$ & $0.09 \mathrm{mg} / \mathrm{L}$ & $0.07 \mathrm{mg} / \mathrm{L}$ \\
\hline Limit of quantification $^{\mathrm{a}}$ & $1.45 \mathrm{mg} / 100 \mathrm{~g}$ & $1.20 \mathrm{mg} / 100 \mathrm{~g}$ & $0.29 \mathrm{mg} / \mathrm{L}$ & $0.24 \mathrm{mg} / \mathrm{L}$ \\
\hline Intra-day precision $(\% \mathrm{CV})^{\mathrm{b}}$ & 1.57 & 1.57 & 8.55 & 8.60 \\
\hline Inter-day precision $(\% \mathrm{CV})^{\mathrm{b}}$ & 0.48 & 0.67 & 0.85 & 0.80 \\
\hline Recovery $(\%)^{\mathrm{c}}$ & 94.16 & 96.38 & 85.66 & 86.78 \\
\hline
\end{tabular}

$R^{2}$ coefficient of determination, $\mathrm{N}$ number of calibration curve standards, CV coefficient of variation.

${ }^{a}$ Limit of detection and quantification were calculated based on signal to noise ratio of 3 and 10, respectively.

${ }^{\mathrm{b}}$ Extracts were reconstituted in $2.5 \mathrm{~mL}$ of acetonitrile in case of EC and $10 \mathrm{~mL}$ in case of R\&G Arabica coffee.

${ }^{\mathrm{c}}$ Calculated from spiked samples at levels of $25 \%$ and $50 \%$ of the initial concentrations of diterpenes in real samples. 
Table 4 Diterpenes and lipids content in different espresso coffees as affected by preparation parameters ${ }^{\mathrm{a}}$

\begin{tabular}{|c|c|c|c|c|c|c|c|c|}
\hline \multirow[b]{2}{*}{ Parameter $^{\mathrm{b}}$} & \multirow[b]{2}{*}{ Level } & \multirow[b]{2}{*}{$\begin{array}{l}\text { Cup size } \\
\text { (mL) }\end{array}$} & \multicolumn{2}{|c|}{ Lipids } & \multicolumn{4}{|c|}{ Diterpenes } \\
\hline & & & $\begin{array}{l}\text { Total lipids }^{\mathrm{c}} \\
(\mathrm{mg} / \mathrm{mL})\end{array}$ & $\begin{array}{l}\text { Oil extraction } \\
\text { yield }(\%)\end{array}$ & $\begin{array}{l}\text { Cafestol }^{\mathrm{c}} \\
(\mathrm{mg} / \mathrm{L})\end{array}$ & $\begin{array}{l}\text { Kahweol }^{\mathrm{c}} \\
(\mathrm{mg} / \mathrm{L})\end{array}$ & $\begin{array}{c}\text { Total } \\
\text { diterpenes } \\
(\mathrm{mg} / \mathrm{L})\end{array}$ & $\begin{array}{c}\text { Total } \\
\text { diterpenes } \\
\text { (mg/cup) }\end{array}$ \\
\hline \multirow{4}{*}{$\begin{array}{l}\text { Coffee weight } \\
\text { (g) }\end{array}$} & 6.5 & $40 \pm 2$ & $2.07 \pm 0.13^{\mathrm{a}}$ & $8.63 \pm 0.06$ & $12.72 \pm 0.38^{\mathrm{a}}$ & $19.20 \pm 0.72^{\mathrm{a}}$ & $31.92 \pm 1.09$ & 1.28 \\
\hline & 7.5 & $40 \pm 2$ & $2.62 \pm 0.11^{\mathrm{b}}$ & $9.47 \pm 0.41$ & $16.06 \pm 1.59^{b}$ & $24.33 \pm 2.38^{\mathrm{b}}$ & $40.39 \pm 3.97$ & 1.62 \\
\hline & 8.5 & $40 \pm 2$ & $2.50 \pm 0.03^{b}$ & $7.97 \pm 0.09$ & $16.10 \pm 1.75^{b}$ & $24.64 \pm 1.66^{\mathrm{b}}$ & $40.74 \pm 3.42$ & 1.63 \\
\hline & 9.5 & $40 \pm 2$ & $2.33 \pm 0.04^{\mathrm{ab}}$ & $6.65 \pm 0.12$ & $17.34 \pm 1.85^{\mathrm{b}}$ & $25.19 \pm 2.64^{b}$ & $42.53 \pm 4.49$ & 1.70 \\
\hline \multirow{4}{*}{$\begin{array}{l}\text { Water quantity } \\
\qquad(\mathrm{mL})\end{array}$} & 30 & $30 \pm 2$ & $2.95 \pm 0.10^{\mathrm{b}}$ & $7.99 \pm 0.03$ & $21.72 \pm 0.35^{\mathrm{c}}$ & $34.08 \pm 0.48^{\mathrm{c}}$ & $55.78 \pm 0.83$ & 1.67 \\
\hline & 40 & $40 \pm 2$ & $2.62 \pm 0.11^{\mathrm{b}}$ & $9.47 \pm 0.41$ & $16.06 \pm 1.59^{b}$ & $24.33 \pm 2.38^{b}$ & $40.39 \pm 3.97$ & 1.62 \\
\hline & 50 & $50 \pm 2$ & $2.02 \pm 0.14^{\mathrm{a}}$ & $9.12 \pm 0.64$ & $11.85 \pm 0.57^{\mathrm{a}}$ & $17.44 \pm 0.82^{\mathrm{a}}$ & $29.29 \pm 1.39$ & 1.46 \\
\hline & 60 & $60 \pm 2$ & $2.21 \pm 0.07^{\mathrm{a}}$ & $11.98 \pm 0.38$ & $15.11 \pm 1.34^{\mathrm{b}}$ & $21.16 \pm 1.84^{\mathrm{b}}$ & $36.28 \pm 3.18$ & 2.18 \\
\hline \multirow{3}{*}{ Particle size } & Very fine & $40 \pm 2$ & $2.66 \pm 0.10^{b}$ & $9.61 \pm 0.04$ & $23.95 \pm 0.30^{\mathrm{b}}$ & $34.91 \pm 0.45^{\mathrm{b}}$ & $58.86 \pm 0.75$ & 2.35 \\
\hline & Fine & $40 \pm 2$ & $2.62 \pm 0.11^{\mathrm{b}}$ & $9.47 \pm 0.41$ & $16.06 \pm 1.59^{\mathrm{a}}$ & $24.33 \pm 2.38^{\mathrm{a}}$ & $40.39 \pm 3.97$ & 1.62 \\
\hline & coarse & $40 \pm 2$ & $1.91 \pm 0.10^{\mathrm{a}}$ & $6.90 \pm 0.36$ & $15.49 \pm 1.29^{\mathrm{a}}$ & $22.47 \pm 1.99^{\mathrm{a}}$ & $37.96 \pm 3.27$ & 1.52 \\
\hline \multirow{3}{*}{$\begin{array}{l}\text { Extraction time } \\
\text { (s) }\end{array}$} & 10 & $40 \pm 2$ & $2.19 \pm 0.07^{\mathrm{a}}$ & $7.91 \pm 0.03$ & $15.73 \pm 1.43^{\mathrm{a}}$ & $23.52 \pm 1.98^{\mathrm{a}}$ & $39.24 \pm 3.41$ & 1.57 \\
\hline & 20 & $40 \pm 2$ & $2.62 \pm 0.11^{\mathrm{b}}$ & $9.47 \pm 0.41$ & $16.06 \pm 1.59^{\mathrm{a}}$ & $24.33 \pm 2.33^{\mathrm{a}}$ & $40.39 \pm 3.97$ & 1.62 \\
\hline & 30 & $40 \pm 2$ & $2.66 \pm 0.14^{b}$ & $9.61 \pm 0.51$ & $20.10 \pm 0.83^{b}$ & $30.66 \pm 1.10^{\mathrm{b}}$ & $50.76 \pm 1.93$ & 2.03 \\
\hline \multirow{3}{*}{$\begin{array}{l}\text { Temperature } \\
\left({ }^{\circ} \mathrm{C}\right)\end{array}$} & 70 & $40 \pm 2$ & $1.60 \pm 0.08^{\mathrm{a}}$ & $5.78 \pm 0.05$ & $12.30 \pm 0.33^{\mathrm{a}}$ & $18.47 \pm 0.47^{\mathrm{a}}$ & $30.77 \pm 0.80$ & 1.23 \\
\hline & 80 & $40 \pm 2$ & $2.30 \pm 0.14^{b}$ & $8.31 \pm 0.51$ & $15.73 \pm 1.43^{b}$ & $23.52 \pm 1.98^{b}$ & $39.24 \pm 3.41$ & 1.57 \\
\hline & 90 & $40 \pm 2$ & $2.62 \pm 0.11^{\mathrm{b}}$ & $9.47 \pm 0.41$ & $16.06 \pm 1.59^{b}$ & $24.33 \pm 2.38^{b}$ & $40.39 \pm 3.97$ & 1.62 \\
\hline \multirow{4}{*}{$\begin{array}{l}\text { Pressure } \\
\text { (bar) }\end{array}$} & 7 & $40 \pm 2$ & $1.59 \pm 0.10^{\mathrm{a}}$ & $5.74 \pm 0.06$ & $13.93 \pm 0.95^{\mathrm{a}}$ & $20.15 \pm 1.27^{\mathrm{a}}$ & $34.08 \pm 2.22$ & 1.36 \\
\hline & 9 & $40 \pm 2$ & $2.62 \pm 0.11^{\mathrm{c}}$ & $9.47 \pm 0.41$ & $16.06 \pm 1.59^{\mathrm{a}}$ & $24.33 \pm 2.38^{b}$ & $40.39 \pm 3.97$ & 1.62 \\
\hline & 11 & $40 \pm 2$ & $2.16 \pm 0.06^{\mathrm{b}}$ & $7.80 \pm 0.20$ & $18.50 \pm 0.80^{\mathrm{b}}$ & $25.83 \pm 1.00^{\mathrm{b}}$ & $44.32 \pm 1.81$ & 1.77 \\
\hline & 14 & $40 \pm 2$ & $2.23 \pm 0.13^{\mathrm{cb}}$ & $8.06 \pm 0.46$ & $14.36 \pm 0.44^{\mathrm{a}}$ & $21.32 \pm 0.74^{\mathrm{a}}$ & $35.68 \pm 1.18$ & 1.43 \\
\hline
\end{tabular}

${ }^{a}$ Values are expressed as mean \pm standard deviation.

${ }^{\mathrm{b}}$ In each variable, other parameters used for preparation of EC was the conditions used for standard EC as follows: fine $R \& G$ coffee $(7.5 \mathrm{~g})$, water quantity $(40 \mathrm{~mL})$, extraction time $(21 \mathrm{~s})$, water temperature $\left(90^{\circ} \mathrm{C}\right)$ water pressure $(9$ bar), with an exception regarding parameter of particle size, where the time of extraction was 35,21 and $10 \mathrm{~s}$ for very fine, fine and coarse ground coffee.

${ }^{\mathrm{c}}$ For each parameter, different letters in the same column indicate significant differences $(p \leq 0.05)$ among variables. 